\title{
STVALL: Hybrid TV for Interactive Language and Content Learning
}

\author{
Alejandro Curado Fuentes \\ University of Extremadura \\ Avda. Universidad, S/N, Cáceres 10003, Spain \\ Email: acurado [AT] unex.es
}

\begin{abstract}
Hybrid television refers to the merging of the Internet and television via a multi-user platform. This technology is used in the STVALL project, providing an educational platform for interactive and adaptive (individual and group) learning. A focus has been the design of specific content activities in the form of learning pills fed into the authoring tool, which stores and distributes them from its knowledge base. The content is classified according to five major subject areas in Education (Science and Nature, Literature and Art, Geography and History, Entertainment and Sports, and Language) and four language levels: Adult (over 12 years of age) / Children (0-12): A1/A2/B1/B2, based on the Common European Framework. Different tags are also assigned for content taxonomy based on the type of content (e.g., monologic vs. dialogic, narrative vs. instructions, etc). Upon interaction with the program, users build a content and language level profile that the system stores and "remembers" for their next session (single- or groupbased). The system has been pre-tested with some groups of adults and children. Some key findings point to users' language levels as a major contributing factor towards the degree of use and motivation with the system whereas group interactivity seems to motivate users more than the single user mode. In sum, because the system is still under development, some ideas for future improvements can be found in users' responses to a post-task survey (for instance, integrating expert-mediated writing and speaking activities).
\end{abstract}

Keywords- Hybrid TV, Interactivity, Learning pills, Language, Content, Education

\section{INTRODUCTION}

The concept of educational television is by no means new, as almost from the onset of TV history, educational content has played an important role publicly by broadcasting pedagogical material (an example is the PBS network in USA). With the evolvement of interactive TV over the past decade, the concept of "t-learning" (Bellotti, Vrochidis, Parissi, Lhoas, Mathevon, Pellegrino, Bo, \& Kompatsiaris., 2008) has been used to refer to the interactive process of learning that takes place when TV audiences leave their more passive roles, and adopt, instead, a more dynamic approach to content viewing. In t-learning, the viewer is stimulated by a combination of audio-visual content and dynamic interaction with the system to accomplish certain goals (Rey-López,, Díaz-Redondo, Fernández-Vilas, Pazos-Arias, López-Nores, GarcíaDuque, Gil-Solla, \& Ramos-Cabrer, 2008).

Nowadays, almost every family member can deploy an individual portable device for entertainment aims. TV may have fallen into disuse ever since other types of content access and preferences took over. Saxbe, Graesch, \& Alvik (2011), over a decade ago, claimed that families still watch TV despite the popularity of other devices. Rigby, Brumby, Gould, \& Cox (2017) noticed a similar situation of TV engagement in which user-adapted programming may thrive along individual and / or group uses of mobile devices. The traditional approach to TV in which content viewing is prescheduled, however, does find a fierce competitor in menu-based, delivery-on-demand, and internet-based resources (Rigby et al., 2017). In turn, the integration of other types of media, such as social TV and stream TV, enrich the technological scenario for easy-to-use synchronization (Van Deventer, Probst, \& Ziegler, 2018). The optimal amalgamation of the different formats and devices can be achieved by the HbbTV standard (Hybrid Broadcast Broadband Television), applied with a fair degree of success in the household context (Gavrila, Popescu, Fadda, Anedda, \& Murroni., 2020).

One example of the technology based on user demands and choices is the hypermedia adaptive system, which allows for content customizing according to user demands and preferences. The notion of adaptive content has already spanned for more than two decades (cf. Brusilovsky, 1998; Brusilovsky, 2001). Adaptive systems manage a user model which stores explicit user information (for instance, age, sex, language level, viewing preferences, and so on) and implicit user data by recording their interaction with the system. An educational area where the use of adaptive hypermedia systems has often correlated with positive learning results is foreign language learning (cf. Cumbreño, Rico-García, CuradoFuentes, \& Domínguez, 2006; Rico-García, Agudo, \& Curado-Fuentes, 2007; Vera-Rodríguez \& Arias-Soto, 2008). The 
content managed can easily adapt to specific user profiles in terms of their language level, objectives, skills, learning needs, and so on. The analysis in these studies also tends to show that students value adaptive content in their learning process as generally positive, especially in terms of written / oral comprehension and vocabulary gain.

The present research, regionally funded by the government of Extremadura, focuses on STVALL (Smart TV Assisted Language Learning) as a multi-user platform where users may exploit content knowledge and linguistic skills. Its HbbTV (Hybrid broadcast broadband Television) technology is supported by a wide range of digital TV brands, more widely in Europe than in other regions (Haase, 2017). This system is built to offer an unlimited number of educational "pills" in the form of interactive activities and challenging tasks, organized and distributed according to subject area macro-labels.

This paper describes the hybrid TV structure, organization, contents, management, as well as the use being made with it by a selected group of users. A part of a regional TV infrastructure project development, STVALL was initially conceived as an updated interactive TV system for educational purposes. It is meant as a reinforcement learning tool for adults and children at different levels of English as a foreign language (EFL) learning. Its content input includes five major subject areas in Education: Science and Nature, Literature and Art, Geography and History, Entertainment and Sports, and Language. The four EFL levels range from A1 to B2, with linguistic items organized according to the Council of Europe's (2020) guidelines. The content learning pills are short interactive activities that challenge the user's knowledge and skills for content decoding and guessing, similarly to trivial pursuit games. The material has been devised and arranged according to the EFL levels, but also classified in terms of interactivity (i.e., timed queries versus untimed content presentations) and type of content (monologic text versus dialogues, or oral input versus written, and so on).

The creation of learning pills has been made with an authoring tool. This process is a key stage so that the activities can adapt to different users' profiles. Adaptation is regarded as a major feature in the project, as user profiles differ in terms of their age, language level, content preferences, performance, and so on. In addition, valuable information is obtained by having different users interact with the system. Then, their impressions and ideas, collected in post-task surveys, may point to strengths and weaknesses for future developments.

In the next section, a literature review of interactive TV and learning projects is presented, followed by the description of the STVALL structure, organization, contents, expert's management section, and its availability to different types of users. Then, some preliminary results derived from the use made by some adults $(\mathrm{N}=8)$ and children $(\mathrm{N}=7)$ are described, and the strengths and weaknesses of the tool discussed in the conclusions.

\section{LITERATURE REVIEW}

Interactive TV has been around for some time now. Pavlov \& Paneva (2006) argued that the information broadcast via interactive TV could be user-friendly and trustworthy. As regards the HbbTV format, Fondevila-Gascón, Del OlmoArriaga, Beriain, Carreras-Alcalde, \& Pesqueira-Zamora (2013) explored different possibilities for the learning context enabled by the HbbTV standard. The following are different projects exploring interactive TV technologies in connection with Education and learning over the past 20 years. The sources are cited in chronological order.

VEMiTV (Damasio \& Quico, 2004) analysed the potential of interactive TV courses as a content learning tool. The lessons included an intelligent tutor called PANDA, which allowed students to interact by means of animated characters and in different subject areas and topics.

Fallahkhair, Pemberton, \& Masthoff (2004) presented a TV system which combined mobile devices and t-learning for language learning. The system allowed users to select the language for the subtitles during a TV program and the possibility of reviewing the vocabulary from the program by choosing specific words and sending them to mobile telephones, where activities could be exploited.

T-MAESTRO (Rey-López et al., 2008) customized educational content for learners via two modules: The "edutainment" section, which provided multimedia-based course material in a more academic manner, and "entercation", with more informal audio-visual output within the lessons.

T-EDUCO (Hupont, Abadía, Baldassarri, Cerezo, \& Del-Hoyo., 2011) proposed a TV system defined as "the first tlearning affective aware tutoring tool" (p. 3). This tool integrates broadcast and broadband technologies with which users' facial expressions can be recorded during their progress with the interactive content (via a set-top box and IP camera). Based on the recorded data (both the users' progress and emotions), education experts could modify or improve content (Baldassarri, Hupont, Abadía, \& Cerezo, 2015).

Bibiloni, Mascaró, Palmer, \& Oliver (2014) worked on a hybrid TV project that allowed for feedback insertion in TV programs (via HbbTV and Augmented Reality). The input items work like benchmarks placed at strategic points during the programs so that, on clicking them, interactive content related to that segment pops up.

Ryu, Kazimierz-Krompiec, Lee, \& Park (2014) designed educational games for English language learning via Smart TV (based on HTML5, JavaScript, and Canvas as supporting architecture). The interactive activities let users play with words by using animated drawings and pictures. 
Ben-Said, Wali, \& Alimi (2018) developed educational content in TV programs by processing audio-visual input within pre-defined thematic sets. For each partitioned segment, similar material could be identified according to user preferences. Then, related learning content merged with the new TV lesson.

Salguero-Serrat, Sánchez, Naranjo, Rico, \& Agudo (2019), following Ben-Said et al. (2018), among others, explored the applicability of the HbbTV standard for language learning in a regional TV system. They implemented a dynamic authoring tool for the management of such content according to different age and language levels.

\section{THE STVALL PLATFORM}

The STVALL project (2018-2020) is based on an educational platform aimed at interactive and customized learning via hybrid TV. Its research group consists of both computer and education specialists (from higher and secondary education). The client / server architecture in this system can be described as follows (Figure 1):

Client section: It provides users with interactional modes so that they may access the content both easily and dynamically. It integrates an initial authoring tool that lets users enter basic internal information such as age, language level, gender, and so on. This is compiled in the user database together with user progress made with the activities.

Server / Host section: It contains three engines (adaptation, recommendation, evaluation), which receive feedback from the educational content and user databases. Based on this information (from content, experts, and users), the webbased authoring tool relays the adapted content to the specific user. The information can also be reviewed by experts for content revision.

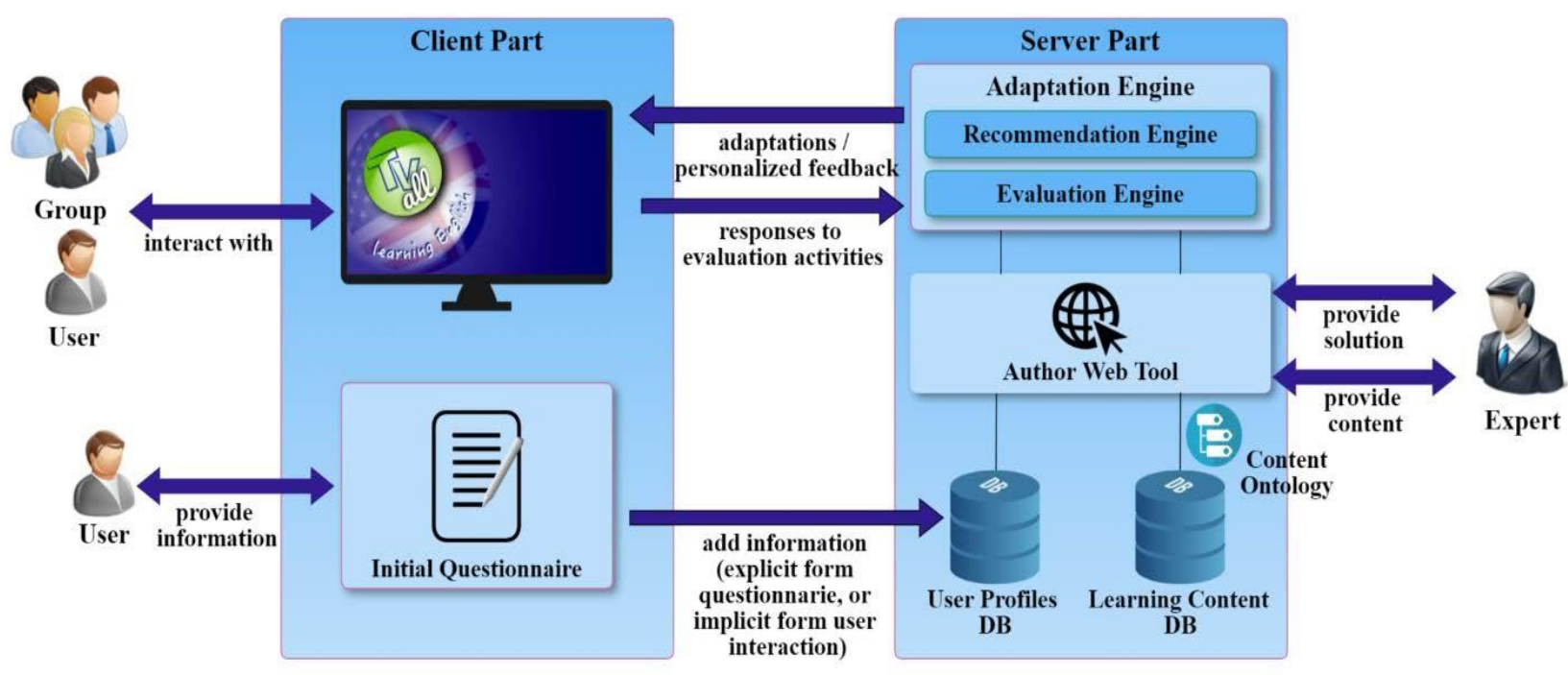

Figure 1: The STVALL Architecture

In the client section, the different user roles are integrated either individually or by groups. Users can access the platform by entering their personal data. If they are new to the system, they must enter all their personal information, but if already registered, they log in with their usernames and passwords. The experts can manage the content via any webbased device (using the authoring tool).

The server consists of two parts:

The storage system, which stores all the educational input (provided by the experts) and all the information related to the user profiles. In the case of user groups, a group model can be created from the user profiles within the group.

The adaptation engine (including the recommendation and evaluation engines) selects those learning pills (single activities) that adapt best to the individual users' profiles or to the group models. The factors considered for adaptation are the EFL targets (i.e., aimed language level), age, preferred topics / subject area, and the users' progress with the system (i.e., their selection of activities, percentage of correct answers, and so on). The recommendation engine provides feedback to users by computing their progress. The calculation of scores, attempts, timing, and other factors during the user's interaction with the content guides future suggestions for learning pills (next time the user enters the system). The evaluation engine stores the correct / incorrect input for each user / group. It automatically sends scores and progress, but it could also store experts' evaluative data if the activities require manually annotated feedback.

The authoring tool is a web-based application created according to the MVC (Model View Controller) pattern. The user interface has been developed with HTML5, CSS3 and JavaScript. This application is also responsive, meaning that it 
is adaptable to any access device thanks to the use of a Bootstrap framework. The implementation of the authoring tool has been divided into three layers: The persistence layer, which enables access to the data using Hibernate technology. The business logic, in charge of processing the information obtained in the previous layer thanks to Spring. The presentation layer, built with Spring MVC technology which allows users to display the information and receive any responses from the system. Finally, in the provision of content to experts and their management of the learning pills, the JSP technology has been applied.

In terms of storage, the system integrates a relational database with all the users' information and their learning pills. The storage section also contains a file database with all the multimedia resources used within the system.

\section{STVALL CONTENT}

As mentioned above, STVALL includes single user and user group adaptabilities. In the first type, a single user responds to learning pills sent by the authoring tool according to his/her profile. The second type involves a more collaborative learning situation in which the users play as a group with pills selected by the tool according to a group model based on the combination of user profiles. For example, if a group were made up of family members (adults and children), the tool would select pills in proportion to the number of players and their profiles in each user category. In addition, a competitive approach can be offered when different users play against each other (individually or by groups). An example could be two families using the platform as two different groups and trying to answer faster, getting more pills correct, and so on.

The pills are content activities and challenges that can be displayed in two forms: As presentations, they provide key content that users can access at will (for example, by listening to audio files about a given concept or idea); and as interactive pills, where content is sent to be answered at that moment, automatically providing users with feedback during and after the activity.

The authoring tool is crucial to meet users' demands and to allow the expert team to devise more appropriate content based on the results. Upon creation of activities as different types of learning pills (described below), the experts can classify the material according to eight parameters (see Table 1).

Table 1: Parameters for expert-based tagging of content in the authoring tool

\begin{tabular}{|l|l|}
\hline User type & Adult / Child \\
\hline Language level & A1 / A2 / B1 / B2 \\
\hline Subject area category & $\begin{array}{l}\text { Science and Nature / Literature and Art / } \\
\text { Geography and History / Entertainment and Sports / } \\
\text { Language }\end{array}$ \\
\hline Language skill & $\begin{array}{l}\text { Written comprehension / Written production / } \\
\text { Oral comprehension / Oral production }\end{array}$ \\
\hline Access mode & Presentation / Interactive \\
\hline Register type & $\begin{array}{l}\text { Professional - academic / News / Fiction - humour / } \\
\text { Conversation }\end{array}$ \\
\hline Discourse function & $\begin{array}{l}\text { Narration / Description / Explanation / Instruction / Definition / } \\
\text { N/A }\end{array}$ \\
\hline Discourse mode & Monologic / Dialogic \\
\hline
\end{tabular}

The first five variables in Table 1 (user type, language level, subject area, language skill, access mode) had already been considered before any content pills were developed, based on the general objectives of the project for educational aims. The other three aspects (register type, discourse function, discourse mode) were introduced at a later stage while content was being collected and designed. Each variable can be accessed as a tag which experts may select and apply upon content creation.

Only one tag per variable can be assigned, except for the register type and discourse function categories, which may present overlapping descriptors. For example, some academic material may be presented with humour or more informally (i.e., academic + humour), or a text may include a description but also instructions (i.e., more than one discourse function). All eight parameters are used for each learning pill. In this way, the activities can be identified more easily in the corpus of learning pills when user preferences and results are processed. 
The expert interface in the authoring tool displays a catalogue of nine possible learning pill templates as different types of activities (see Figure 2 for a screenshot).

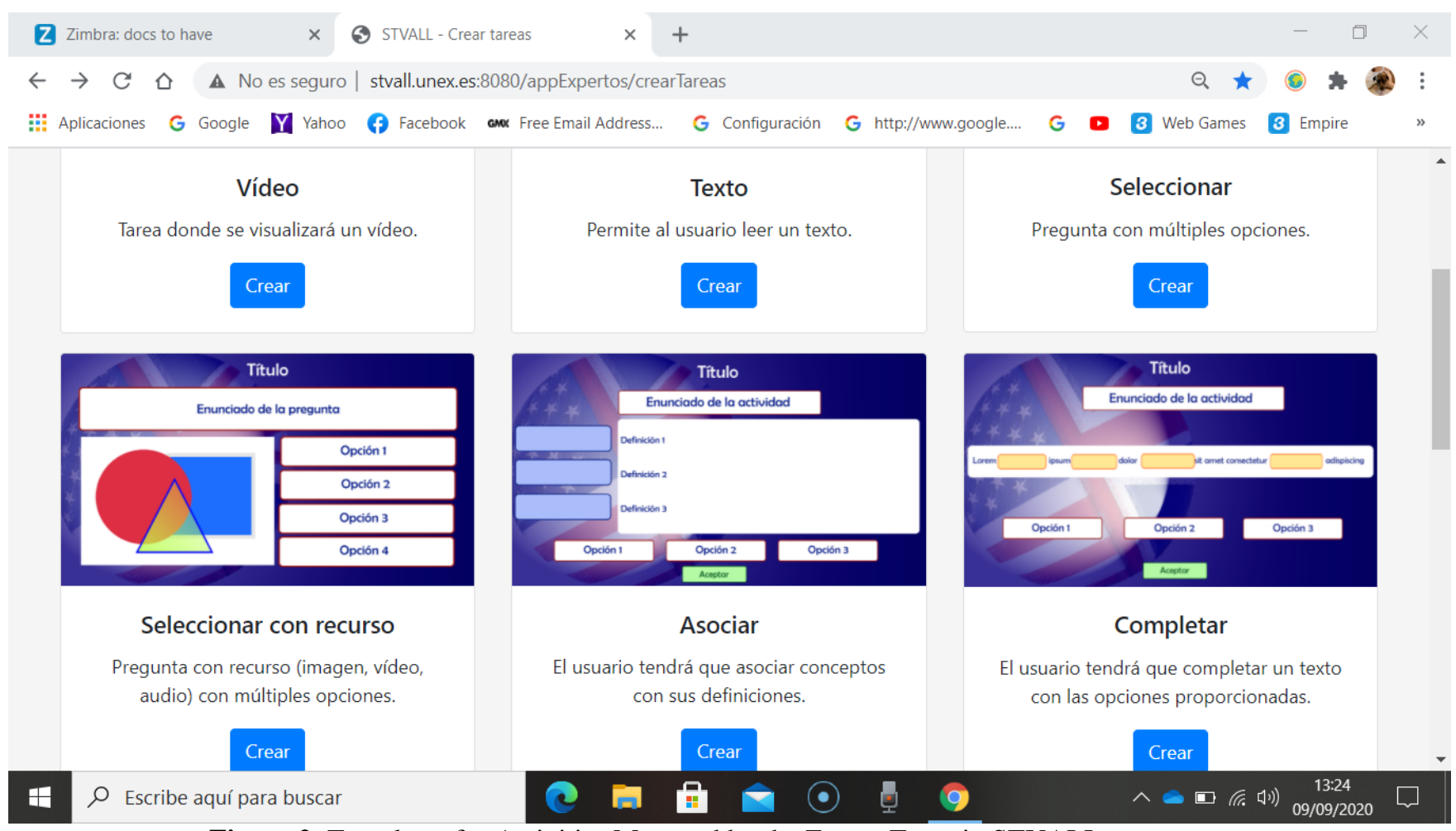

Figure 2: Templates for Activities Managed by the Expert Team in STVALL

The different types of learning pills are:

Text presentation: Non-interactive short text related to the subject content.

Video presentation: Non-interactive audio-visual material related to the subject content.

Multiple choice: Interactive question that the user must answer by choosing only one possible option after reading a given output.

Multiple choice with a resource: Interactive question that the user must answer by choosing only one possible item after audio, graphical, or audio-visual output has been displayed.

Matching: Interactive challenge requiring the user to match different answers after text, graphic, audio, and / or audiovisual output have been accessed.

Fill-in-the-gaps: Interactive challenge to complete a short text by choosing specific words from a box (audio or audiovisual output may be included).

Sequence: Interactive challenge to answer some questions during the display of a text, audio, or audio-visual content.

Writing: Interactive challenge to write a short text. In this type, a different device (for example, a smart phone) must be used as a secondary instrument where users enter information. The learning pill is viewed on TV with the instructions and / or recommendations for this challenge, which run according to existing templates. For example, the output could be a text to be completed as a "gapping" activity, or take the form of a "complete the text" template in which the user must finish sentences with specific words from a box. It could also consist of a "matching" challenge in which the user must reorder some paragraphs to form a story, and so on. All of these are evaluated automatically by the tool. However, when more text must be entered, for example, when open answers must be developed, human intervention is required for correction and feedback.

Speaking: Similarly, the user will have to deploy a secondary device to record his/her oral input requested in the speaking challenge. The template options would range from single words, which the automatic voice recognition in the system will process, to longer, more elaborate answers that require human intervention.

\section{STVALL MANAGEMENT}

The expert's creation of the learning pills consists of two stages:

Assigning features to the activity. Experts are required to fill in the information related to the activity being created. The material must be described and inserted at this stage, e.g., a video from YouTube, or an audio file to be uploaded. These resources must be compatible with the HbbTV version 2.0.1 standard (ETSI, 2016). In the case of images, the 
formats accepted are JPEG, GIF and PNG; for video files, MP4, and for audio formats, MP3. For YouTube videos (licensed with creative commons), the player for hybrid TV is YouTube Player API (Google Developers, 2014).

Metadata insertion. Experts must enter metadata in the activity being created so that the recommendation engine can assign the activity to a given single user profile or group model. The eight parameters shown in Table 1 above are displayed at this stage for experts to choose from.

The authoring tool also allows experts to manage already created learning pills. A list of created activities (see Figure 3 ) is displayed in the management section for experts to choose from and revise (modify or delete) at any time. This is an important utility so that the learning pills can be changed due to external demands (for instance, because the audio-visual output is no longer available or the users value the activity negatively).

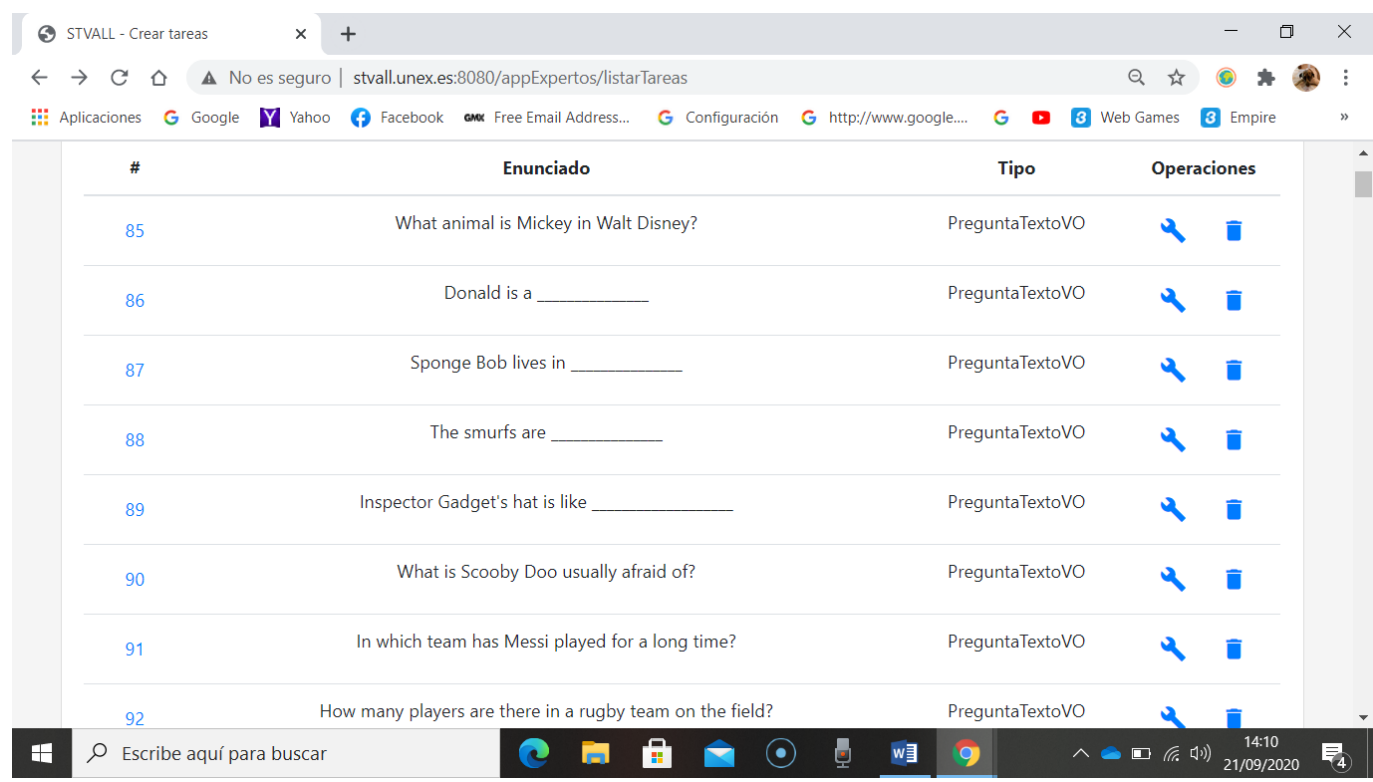

Figure 3: Example of Learning Pills in the Management tool

The viewing mode of the completed and validated learning pill becomes the TV content output. Figure 4 illustrates a matching activity based on a video for children at B1/B2 levels. Figure 5 illustrates the same type of activity at lower language levels. The main difference is the language complexity used in the resources (i.e., vocabulary, grammar, type of discourse, voice speed, and so on).

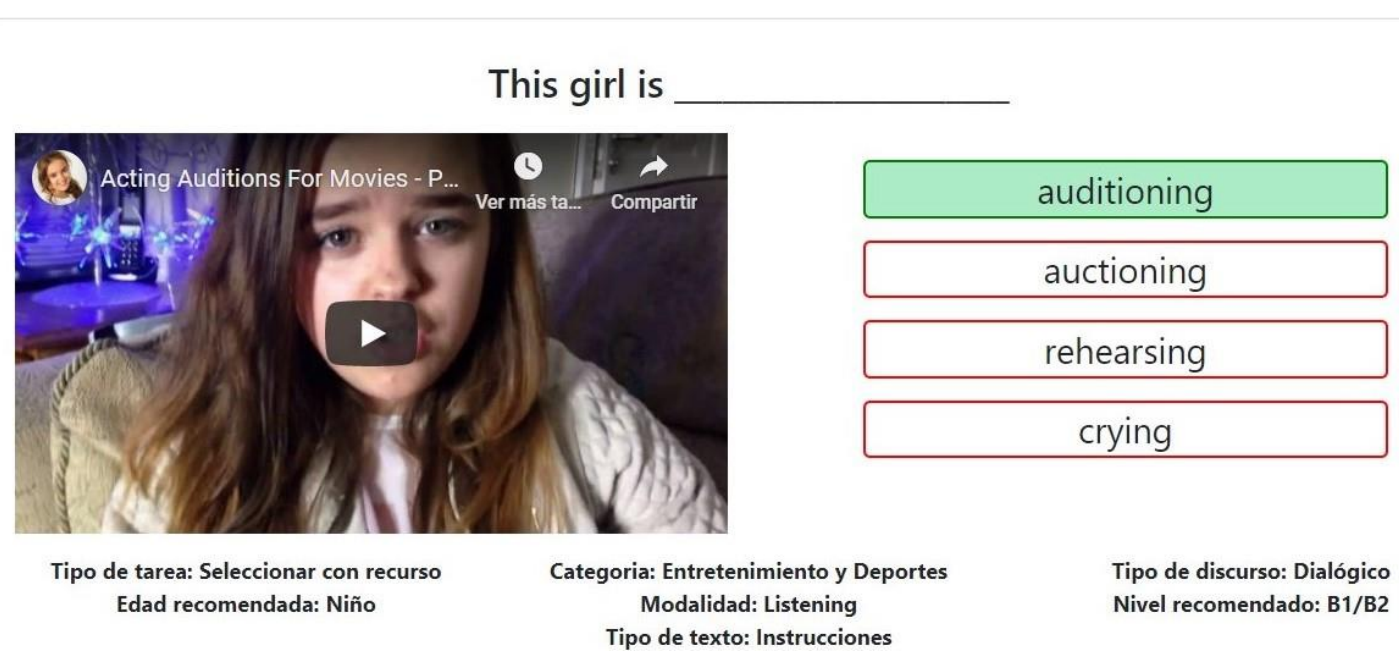

Figure 4: Matching Activity for Children at B1 / B2 Levels 


\section{Who gets the answer right about the noise made by the duck?}

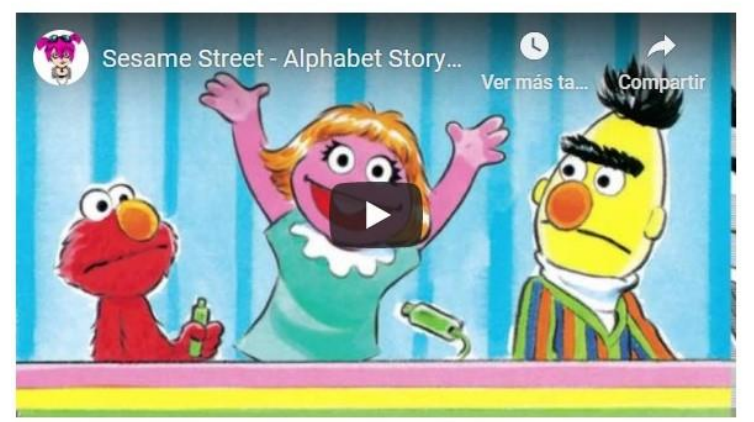

\begin{tabular}{l}
\hline Elmo \\
\hline Bert \\
\hline Prairie Dawn \\
\hline Guy Smiley \\
\hline
\end{tabular}

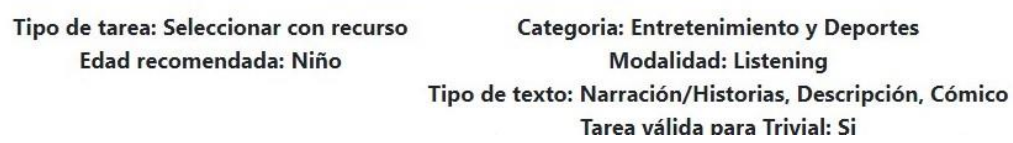

Tipo de discurso: Dialógico

Nivel recomendado: A1/A2

Figure 5: Matching Activity for Children at A1 / A2 Levels

When using the tool with groups, the learners can operate in a collaborative learning mode. Students must select their profiles so that the recommendation engine can build a joint user model based on all the individual user models involved. Once the joint user model has been set, the engine recommends the activities for this model to integrate participation. As in the previous mode, learning pills with different themes and modality are presented, but must be solved jointly by the group of learners. When they decide to leave the platform, the engine adds to each user model the progress made by the group, with all points obtained and the history of their performance thus far.

In the competitive mode, it is possible to record the participation of users that have not previously registered in the system. This option is called "invited users", made available so that a more dynamic feature can be displayed for more participants. For invited users, the engine randomly selects an activity at any EFL level. In this line, an activity must be completed before the time runs up (Figure 6), with each user participating by turn-taking and adding to their game board the points obtained. The user who first reaches the maximum score will be the winner of the game. When finished, the engine stores the progress for each user. In the case of registered users, this performance is added up in their profiles.

\section{In what ocean can you find these sharks, called the Great White, the largest predatory fish in the world?}
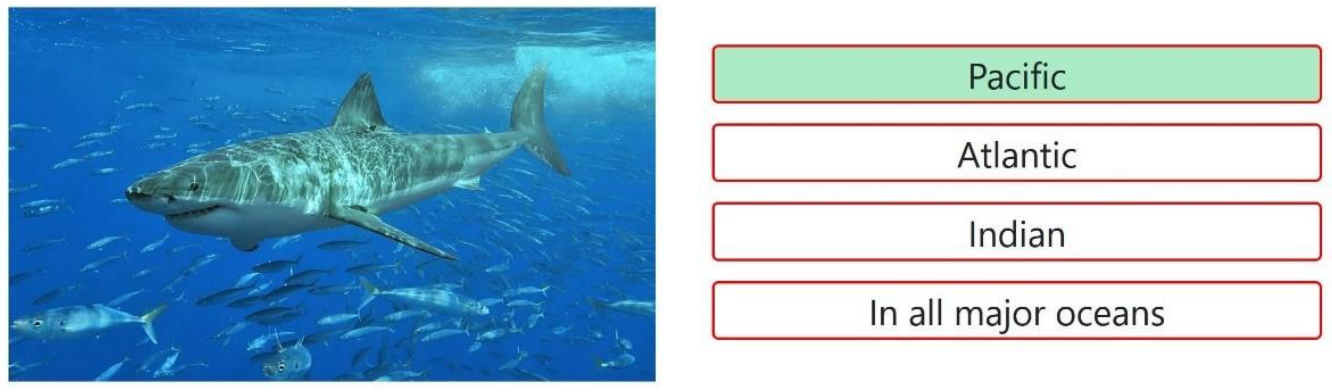

In all major oceans

jesalguer

ngillope

Points: 10

Points: 10

Figure 6: Competitive Mode with Registered and Invited Users

\section{STVALL USERS}

Once the content was created and organized in STVALL, using it with outside participants becomes a key procedure for the evaluation of the tool. So far, 15 people (eight adults and seven children) have used STVALL (April - July, 2020. The 15 users had access to 1000 interactive activities and 500 presentations. Four users (two adults and two children) 
interacted with the system in the single mode alone. The remaining 11 users interacted as both single users and groups, and seven (two adults and five children) played in the competitive mode.

Table 2 compares each user's interaction according to the percentage derived from the proportion between his/her accessed learning pills and those correctly answered in the single mode. The table includes each user's EFL level for contrastive aims.

Table 2: Use made in the single mode and correct answers for each user

\begin{tabular}{|l|l|l|l|}
\hline \multicolumn{1}{|c|}{ User / EFL level } & \multicolumn{1}{|c|}{ Correct pills } & Percentage \\
\hline Adult 1 / B1 & 120 & 57 & 47.5 \\
\hline Adult 2 / B2 & 311 & 286 & 91.9 \\
\hline Adult 3 / B2 & 390 & 251 & 64.3 \\
\hline Adult 4 / B2 & 310 & 220 & 70.9 \\
\hline Adult 5 / A2 & 312 & 121 & 38.7 \\
\hline Adult 6 / B2 & 512 & 477 & 93.1 \\
\hline Adult 7 / B1 & 233 & 165 & 73.9 \\
\hline Adult 8 / B2 & 317 & 300 & 94.6 \\
\hline Child 1 / B1 & 78 & 9 & 39.7 \\
\hline Child 2 / A2 & 33 & 9 & 27.2 \\
\hline Child 3 / A1 & 31 & 7 & 29 \\
\hline Child 4 A1 & 30 & 53 & 23.3 \\
\hline Child 5 / A1 & 33 & 30 & 15.1 \\
\hline Child 6 / B2 & 157 & 57.9 \\
\hline Child 7 / B1 & 41 & 73.1 \\
\hline
\end{tabular}

For both adults and children, the correlation between their EFL levels and number of correct interactive learning pills (Figure 7) is positive strong. According to the results, the higher their English language level is, the higher the percentage of activities they answer correctly. In turn, lower EFL levels correlate with lower numbers of learning pills accessed and answered correctly.

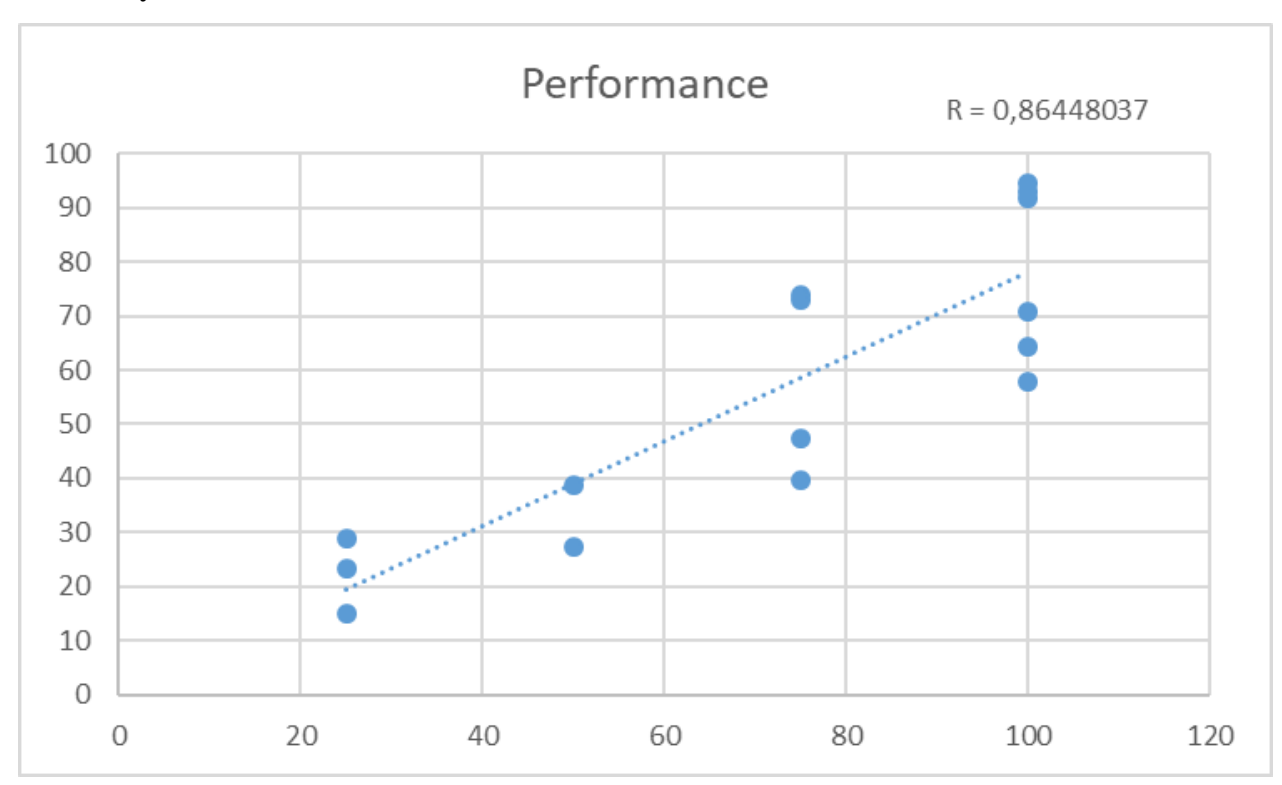

Figure 7: Correlation between Language Level and Performance

The subject areas where more correct answers are recorded were first, Science (six people) and second, Entertainment (five). This progress differs from their alleged favourite topics (in the survey-See Appendix). An R coefficient of - 
0.07595545 in their performance with Science versus their favourite topic scores indicates that there is no correlation, and -0.2222222 in Entertainment is too weak as an indicator of correlation with a preferred subject area.

As regards their group mode use, Table 3 includes the group members (user numbers correspond to Table 2 above) and their performances. All the groups consist of family members, and the percentages refer to the proportions of their correct answers in a subject category versus their total number of correct scores in all the sessions.

Table 3: Percentage results for each subject category in the group mode

\begin{tabular}{|l|l|l|l|l|}
\hline & Group 1 & Group 2 & Group 3 & Group 4 \\
\hline Members & Adults 2 and 3 & $\begin{array}{l}\text { Adult 6; } \\
\text { Children 1, 2, 3 }\end{array}$ & Adults 7 and 8 & $\begin{array}{l}\text { Adult 1; } \\
\text { Children 4, 5 }\end{array}$ \\
\hline Science & 28.2 & 30.9 & 30.1 & 32 \\
\hline Entertainment & 14.8 & 27.8 & 16.1 & 27.1 \\
\hline History & 25.6 & 13.7 & 12.9 & 9.7 \\
\hline Language & 22.9 & 20.6 & 19.3 & 29.1 \\
\hline Literature & 8.3 & 6.8 & 21.5 & 1.9 \\
\hline
\end{tabular}

The percentages are higher for Science in all the groups, in agreement with most single users' results. Entertainment does not come second as in the single mode (only in Group 2). Thus, it seems that the groups' performances tend to vary, with more correct answers achieved in a wider range of categories.

Groups 2 and 4 competed in a session that lasted 54 minutes, accessing all categories according to a selection of pills made by the authoring tool at an intermediate level (these users had both advanced and beginner levels). Group 2 answered more pills correctly (65 versus 12$)$.

\section{SURVEY RESULTS}

A total of 11 users completed a 30-question survey (see Appendix) after their interaction with STVALL. Children 2 , 3,4 , and 5 (cf. Table 2) were excluded because of their young age (under 10). No quantitative analysis was conducted due to the low number of respondents, but correlation coefficients between some item answers were calculated to examine whether some features in the system could potentially relate to others (i.e., whether scores correlated). There were no outliers found in any scores according to the calculation of inter-quartile ranges for upper bound and lower bound values in each survey question.

No correlations were found between the first three personal questions (i.e., age, sex, language level) and other items, for example, enjoying the system (item 4), or the number of times using it (item 5), as most respondents said they liked it and played between one and five times. Only adults 3 and 7 answered "No comment" in item 4, and adult 6 and child 1 played between five and 10 times.

As regards the potential correlation of the scores in other features of the system, strong positive correlations were identified for items 15 and 16, 17 and 19, 17 and 20, and 18 and 21. In the first case, the three respondents who competed in groups gave high scores to the group and competing modes. In the second correlation, the comparison of question 17, about their evaluation of the interactive activities, and item 19, about the audio-visual content, led to a correlation of $\mathrm{R}=$ 0,85135135 (see Figure 8). Question 17 with question 20 (audio content) also produced a positive strong correlation (0,79035572). Finally, the comparison of item 18 (presentation pills) with 21 (text content) produced a positive correlation of $\mathrm{R}=0,62493243$. 


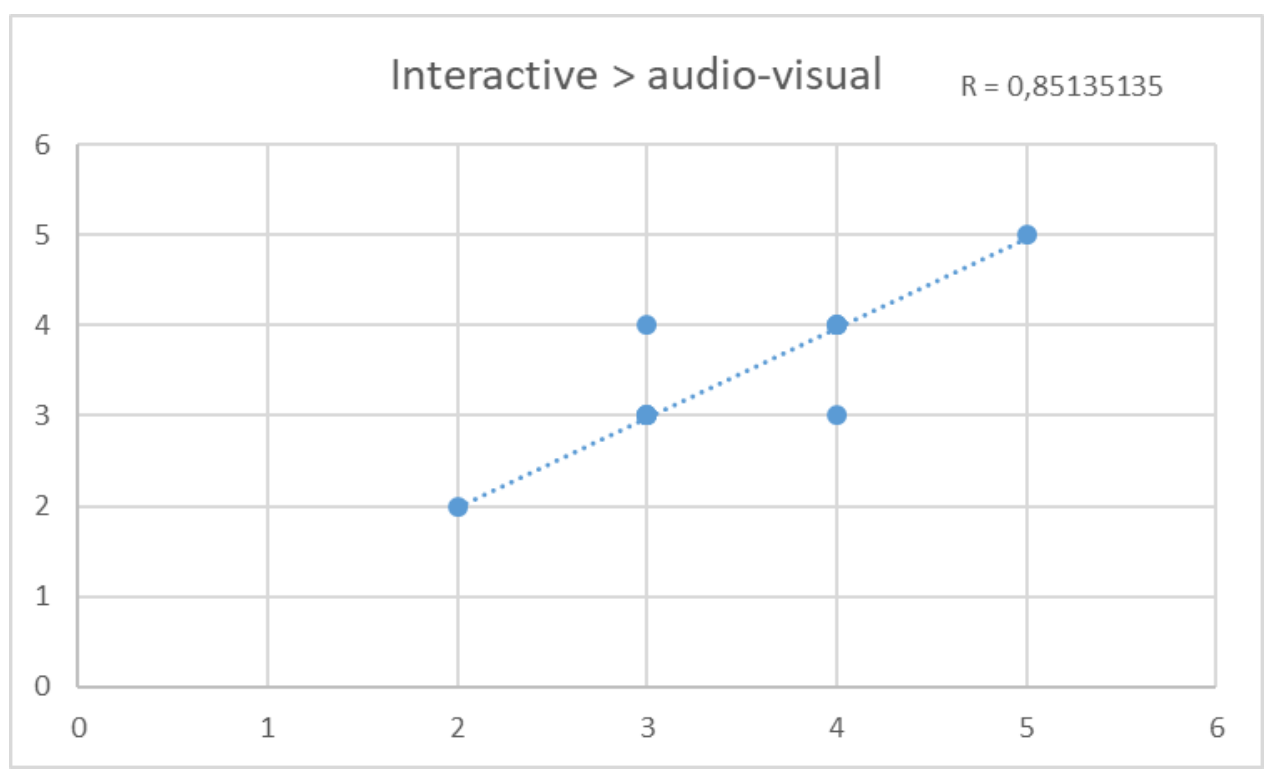

Figure 8: Strong Positive Correlation (Questions 17 and 19)

Other item comparisons yield weak correlations (either positive or negative). For example, liking the single user mode (item 14) and the interactive pills (item 17) denotes $\mathrm{R}=0,29382824$, and group mode (item 15) with interactive pills has $\mathrm{R}=-0,26991054$. Other examples of no correlation are items 17 (interactive pills) and 21 (liking text content), and item 17 with any subject category (i.e., questions 22-26 in the survey).

In question 9, seven users answered "Listening" as the best-developed language skill, two respondents said Reading, and two others marked None. In question 10 concerning writing, seven answered YES, two said No, and two "No comment". In question 12 on speaking, nine answered YES and two "No comment". This means that a reinforcement of writing and speaking activities are demanded by most users. These activities would require both automatic and human evaluation, and are already devised in STVALL but not available to users. Figure 9 shows a proposal for how writing activities can be saved so that experts can check and evaluate them at a future stage.

\begin{tabular}{cccc} 
& \multicolumn{3}{c}{ Tareas pendientes de corregir } \\
\hline$\#$ & ID Tarea & Tipo & ID Usuario local \\
\hline 1 & 975 & Writingvo & 1 \\
\hline 2 & 976 & Witingvo & 1 \\
\hline 3 & 978 & Witingvo & 1 \\
\hline 4 & 979 & & 1 \\
& &
\end{tabular}

Figure 9: Writing Activity Storage for Human Evaluation

Question 11 elicited five comments, and question 13, six. The main ideas conveyed in \#11 referred to the use of the system for grammar improvement, especially in relation to the use of articles and prepositions. Other comments referred to the need for more automatic exercises providing appropriate vocabulary in sentences. Only one person noted the importance of human mediation for writing activities. In item 13, most people expressed the need for voice recognition activities. One respondent put forward that an option for online communication with other users would notably enhance the system's features.

Finally, questions 27-30 focuses on the possible educational aspects of the tool for home use. Figure 10 displays the scores given to each item. Based on the compared data, more positive reactions result from questions 28 ("STVALL is fun to use"), 29 ("STVALL is good for family use"), and 30 ("I would use STVALL in the future"). 


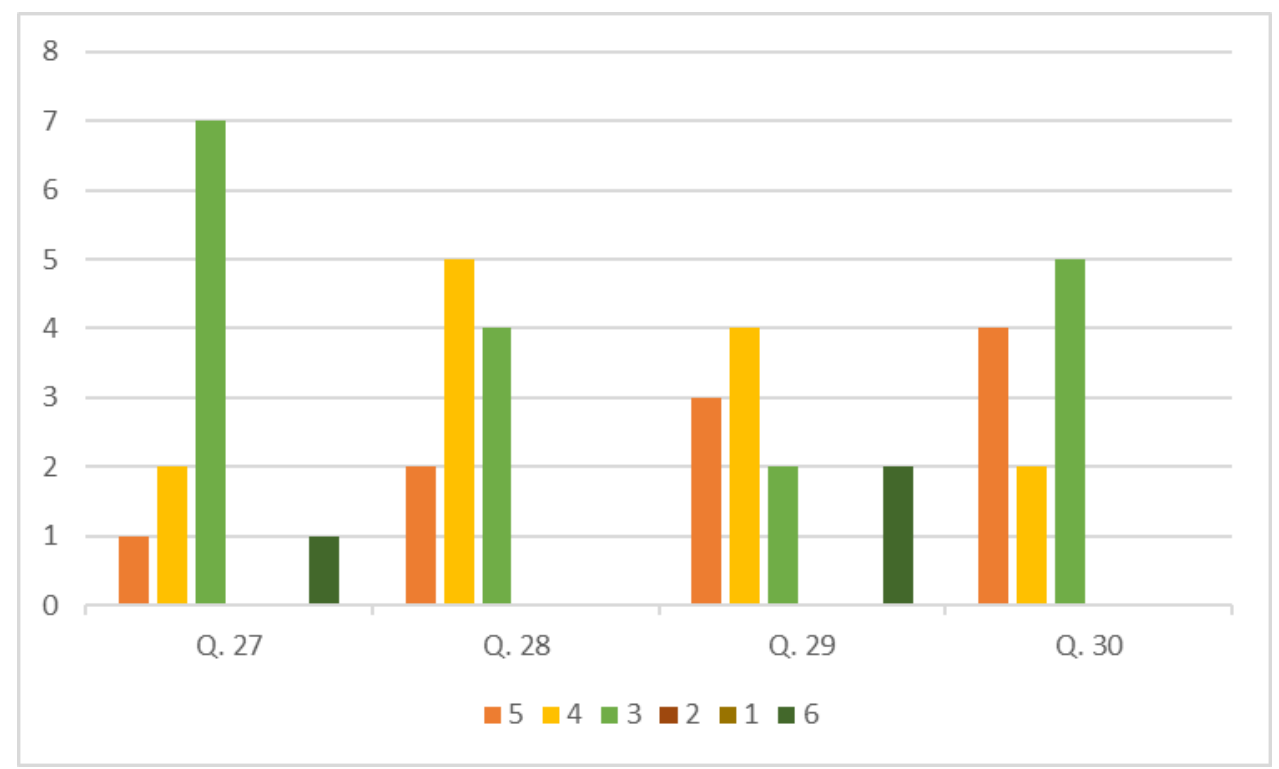

Figure 10: Answers to Questions 27-30

\section{CONCLUSIONS}

This paper has described STVALL as a hybrid TV affordance for content and language learning in family / home settings. Its structure and content can facilitate scenarios of user interactivity and educational gamification. Thanks to its authoring tool, experts can revise and improve the insertion of learning pills in the form of trivial pursuit challenges, which adapt to user profiles according to personal, socio-educational, and EFL features. Groups can also play in STVALL and compete as families from home.

The data collected with 15 users so far have provided some initial feedback in terms of performance and impressions with the tool. One main observation is that a higher English language level seems to favour a better performance while lower level users tend to access fewer learning pills and score lower. Children, in particular, demonstrate less interest when playing in the single mode, but not in the group mode with their parents and siblings. Access and correct answers to the content also vary between single user and group modes. In both cases, users tend to guess more answers correctly in Science, but as a second choice, the subject order changes. In addition, lower EFL users tend to participate more when interacting in the group mode with higher EFL learners.

According to the surveys, no specific content was favoured, i.e., the users did not allocate high scores to any particular subject area, even if they generally obtained higher scores in Science when they played. However, they seem to appreciate listening and video materials more, as the higher scores there show. Interactivity not correlating with text content, and text correlating with presentations, may entail that users consider text as less attractive for interactivity. Most presentations include text only, and fewer add graphic, audio, or video material. Further developments thus suggest the inclusion of more oral / aural resources, and less text, in presentations.

A human evaluator behind the more complex production (writing and speaking) skills is also demanded. Figure 11 shows an example of a text editor proposal already in progress for writing correction. This editor has not been tested yet, but it seems user-friendly enough for the teachers to use in their role as writing mediators, working with different tags and labels (grammatical or lexical errors, connectors, missing items, and / or any other language learner error aspects deemed as necessary). It is based on the execCommand method, included in JavaScript (Mozilla developers, 2019). 


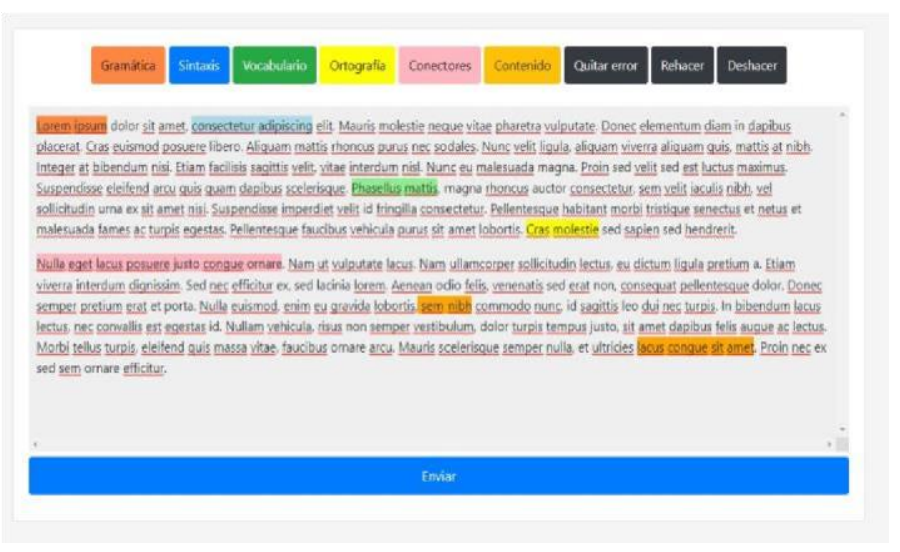

Figure 11: Text editor for writing pills

For speaking, the solution could be that experts access an oral input section where the content recorded by the users has been stored. Experts can then use a text window for any comments and corrections to be inserted and sent to the user.

In conclusion, STVALL has begun on a high note and shows promising results. In addition to the improvement of the content activities and design needed, further testing with different types of users will be hopefully conducted in the future (for instance, in schools and faculties with different children and adults). Based on the compared data, more reactions should be analysed and contrasted with user performances in order to evaluate the tool as a dynamic learning experience, valid for both fun and learning aims in school and home environments.

\section{ACKNOWLEDGEMENT}

I would like to recognize and thank my research group GexCALL (Computer-Assisted Language Learning Group in University of Extremadura) for their work on this project, without which much of the information in this paper would not have been obtained. Our regional project has been funded by the Government of Extremadura with Agreement number \# IB 16160 .

\section{REFERENCES}

Baldassarri, S., Hupont, I., Abadía, D., \& Cerezo, E. (2015). Affective-aware tutoring platform for interactive digital television. Multimed Tools Appl, 74, 3183-3206. DOI:doi.org/10.1007/S11042-013-1779-z.

Bellotti, F., Vrochidis, S., Parissi, E., Lhoas, P., Mathevon, D., Pellegrino, M., Bo, G., \& Kompatsiaris, I. (2008). A tlearning courses development and presentation framework. IEEE Multidisplinary Engineering Education Magazine, $3(3), 69-76$.

Ben-Said, O., Wali, A., \& Alimi, A.M. (2018). A new system for TV program contents improvement using a semantic matching technique. In J.R. Villar, E. A. de la Cal, A. Herrero, H. Quintián, \& J.A. Sáez (Eds.), Hybrid artificial intelligent systems (pp. 246-250). Springer.

Bibiloni, T., Mascaró, M., Palmer, P., Oliver, A. (2014). Augmented reality on HbbTV, an hypervideo approach. $9^{\text {th }}$ Iberian conference on information systems and technologies (CISTI) (pp. 743-748). IEEE.

Brusilovsky, P. (1998). Web-based education for all: A tool development adaptative courseware. Computer Networks and ISDN Systems, 30(17), 291-300.

Brusilovsky, P. (2001). Adaptive hypermedia. User Modeling and User Adapted Interaction, 11(1-2), 87-110.

Council of Europe (2020). Common European framework of reference for languages: Learning, teaching, assessmentcompanion volume. Council of Europe Publishing.

Cumbreño, A., Rico-García, M., Curado-Fuentes, A., \& Domínguez, E. (2006). Developing adaptive systems at early stages of children's foreign language development. ReCALL, $18(1), \quad 45-62$. DOI: https://doi.org/10.1017/S0958344006000413.

Damasio, M., \& Quico, C. (2004). T-learning and interactive television edutainment: The Portuguese case study. Proceedings of ED-MEDIA 2004 - World conference on educational multimedia, hypermedia \& telecommunications (pp. 4511-4518). AACE. 
ETSI

(2016).

HbbTV

2.0.1

https://www.etsi.org/deliver/etsi_ts/102700_102799/102796/01.04.01_60/ts_102796v010401p.pdf.

specification.

Fallahkhair, S., Pemberton, L., \& Masthoff, J. (2004). A dual service scenario for informal language learning: Interactive television meets the mobile phone. Proceedings of the $4^{\text {th }}$ IEEE international conference on advanced learning technologies (pp. 16-20). IEEE Computer Society.

Fondevila-Gascón, J.F., Del Olmo-Arriaga, J.L., Beriain, A., Carreras-Alcalde, M., \& Pesqueira-Zamora, M.J. (2013). Educational possibilities in the internet-television intersection: The HbbTV standard. International conference on education and new developments (pp. 35-37).

Gavrila, C., Popescu, V., Fadda, M., Anedda, M., \& Murroni, M. (2020). On the suitability of HbbTV for unified smart home experience. IEEE Transactions on Broadcasting, 99, 1-10.

Google Developers (2004). YouTube player API reference for Iframe embeds. https://developers.google.com/youtube/iframe_api_reference?hl=es.

Haase, H.E. (2017). HbbTV country review: Rest of the world. In HbbTV symposium (pp. 45-49).

Hupont, I., Abadía, D., Baldassarri, S., Cerezo, E., \& Del-Hoyo, R. (2011). TEDUCO: A t-learning tutoring tool that cares. International Journal on Artificial Intelligence Tools, 20(4), 639-661.

Mozilla Developers (2019). Document.exe command. https://developer.mozilla.org/es/docs/Web/API/Document/execCommand.

Pavlov, R., \& Paneva, D. (2006). Interactive TV-based learning, models and standards. In L. Böszörményi, \& I. Simonics (Eds.), Methods and Tools for Development of Semantic Enabled Systems and Services for Multimedia Content, Interoperability and Reusability (pp. 70-99). HUBUSKA.

Rey-López, M., Díaz-Redondo, R., Fernández-Vilas, A., Pazos-Arias, J., López-Nores, M., García-Duque, J., Gil-Solla, A., Ramos-Cabrer, M. (2008). T-MAESTRO and its authoring tool: Using adaption to integrate entertainment into personalized t-learning. Multimed Tools Appl, 40, 409-451.

Rico-García, M., Agudo. J.E., \& Curado-Fuentes, A. (2007). The application of adaptive hypermedia systems to specific / linguistic communicative learning traits. In A. Curado-Fuentes, P. Edwards, \& M. Rico-García (Eds.), Approaches to specialised discourse in higher education and professional contexts (pp. 156-181). Cambridge Scholars Press.

Rigby, J.M., Brumby, D., Gould, S., \& Cox, A.L. (2017). Media multi-tasking at home: A video observation study of concurrent TV and mobile device usage. TVX '17: ACM international conference on interactive experiences for TV and online videopp (pp. 3-10). Association for Computing Machinery. DOI: https://doi.org/10.1145/3077548.3077560.

Ryu, D., Kazimierz-Krompiec, P., Lee, E., \& Park, K. (2014). A serious game design for English education on smart TV platform. The 18th IEEE international symposium on consumer electronics (ISCE 2014) (pp. 1-2). IEEE. DOI: 10.1109/ISCE.2014.6884479.

Salguero-Serrat, J., Sánchez, H., Naranjo, M.J., Rico, M., \& Agudo, J.E. (2019). STVALL: HbbTV-based adaptive system for English learning through interactive TV. Proceedings of EdMedia + innovate learning (pp. 1520-1525). AACE.

Saxbe, D., Graesch, A., \& Alvik, M. (2011). Television as a social or solo activity: Understanding families' everyday television viewing patterns. Communication Research Reports, 28(2), 180-189.

Van Deventer, M.O., Probst, M., \& Ziegler, C. (2018). Media synchronisation for television services through HbbTV. In M. Montagud, P. Cesar, F. Boronat, \& J. Jansen (Eds.), MediaSync (pp. 7-18). Springer. DOI:https://doi.org/10.1007/978-3-319-65840-7_18

Vera-Rodriguez, E., \& Árias-Soto, L.D. (2008). Development of strategies to teach English through an interactive game: A journey to Britannia. Folios, 28(2), 120-136. 


\section{APPENDIX}

1. How old are you?

Survey questions

a. $\quad 0-12$ b. Over 12

2. What is your gender?

a. Male b. Female

3. What is your English language level?
a. A
b. A2 c.

4. Did you enjoy using STVALL?

a. Yes b. No c. No comment

5. How many times did you use STVALL?

a. 1-5 times b. 5-10 times c. More than 10 times

6. Which mode did you use?

a. Single user b. Group mode c. Both modes

7. Did you use it to compete against other players?

a. Yes b. No

8. If you answered Yes to question 7, did you compete

a. As a single user b. As a group c. As both

9. Which language skill do you think STVALL is best for?
a. Reading
b. Writing
c. Listening
d. None

10. Would you like to have more writing activities in STVALL?
a. Yes
b. No
c. No comment

11. If you answered Yes to question 10, give some examples of writing activities you would like STVALL to add:

12. Would you like to have speaking activities in STVALL?
Yes
b. No
c. No comment

13. If you answered Yes to question 12, give some examples of speaking activities you would like STVALL to add:

From 1 (poor) to 5 (excellent), rate the following:

14. Single user mode

\begin{tabular}{|c|c|c|c|c|}
\hline 1 & 3 & 4 & 5 & N/A \\
\hline 15. & \multicolumn{4}{|c|}{ Group mode } \\
\hline 1 & $2 \quad 3$ & 4 & 5 & N/A \\
\hline 16. & \multicolumn{4}{|c|}{ Competing mode } \\
\hline 1 & $2 \quad 3$ & 4 & 5 & N/A \\
\hline 17. & \multicolumn{4}{|c|}{ Interactive pills } \\
\hline 1 & $2 \quad 3$ & 4 & 5 & N/A \\
\hline 18. & \multicolumn{4}{|c|}{ Presentation pills } \\
\hline 1 & $2 \quad 3$ & 4 & 5 & N/A \\
\hline 19. & \multicolumn{4}{|c|}{ Audio-visual content } \\
\hline 1 & $2 \quad 3$ & 4 & 5 & N/A \\
\hline 20. & \multicolumn{4}{|c|}{ Audio content } \\
\hline 1 & 23 & 4 & 5 & N/A \\
\hline 21. & \multicolumn{4}{|c|}{ Text content } \\
\hline 1 & $2 \quad 3$ & 4 & 5 & N/A \\
\hline 22. & \multicolumn{4}{|c|}{ Science category } \\
\hline 1 & $2 \quad 3$ & 4 & 5 & N/A \\
\hline 23. & \multicolumn{4}{|c|}{ History category } \\
\hline 1 & 23 & 4 & 5 & N/A \\
\hline 24. & \multicolumn{4}{|c|}{ Entertainment category } \\
\hline 1 & $2 \quad 3$ & 4 & 5 & N/A \\
\hline 25. & \multicolumn{4}{|c|}{ Language category } \\
\hline 1 & $2 \quad 3$ & 4 & 5 & N/A \\
\hline 26. & \multicolumn{4}{|c|}{ Literature category } \\
\hline 1 & $2 \quad 3$ & 4 & 5 & N/A \\
\hline 27. & \multicolumn{3}{|c|}{ STVALL is good for learning } & \\
\hline 1 & $2 \quad 3$ & 4 & 5 & N/A \\
\hline 28. & \multicolumn{4}{|c|}{ STVALL is fun to use } \\
\hline 1 & $2 \quad 3$ & 4 & 5 & N/A \\
\hline
\end{tabular}


29. STVALL is good for family use

$\begin{array}{lllllll}1 & 2 & 3 & 4 & 5 & \text { N/A }\end{array}$

30. I would use STVALL more in the future

$\begin{array}{lllllll}1 & 2 & 3 & 4 & 5 & \text { N/A }\end{array}$ 